Research Article

\title{
Spatiotemporal Evolution of Earthquakes in Longmenshan Fault and Adjacent Area, before and after the 2008 Wenchuan Earthquake
}

\author{
Gang Fan $\left(\mathbb{D},{ }^{1,2}\right.$ Jun Wang $\left(\mathbb{D},{ }^{3}\right.$ Shunchao Qi $\mathbb{D},{ }^{1}$ Gongda Lu, ${ }^{1}$ Xingguo Yang $\mathbb{D},{ }^{1}$ \\ and Jiawen Zhou $\mathbb{D}^{1}$ \\ ${ }^{1}$ College of Water Resource and Hydropower, Sichuan University, Chengdu 610065, Sichuan, China \\ ${ }^{2}$ State Key Laboratory of Geohazard Prevention and Geoenvironment, Chengdu University of Technology, \\ Chengdu 610059, Sichuan, China \\ ${ }^{3}$ Sichuan Highway Planning Survey Design and Research Institute Ltd., Chengdu 610041, Sichuan, China
}

Correspondence should be addressed to Jiawen Zhou; jwzhou@scu.edu.cn

Received 5 June 2021; Revised 15 October 2021; Accepted 10 November 2021; Published 24 November 2021

Academic Editor: Annalisa Greco

Copyright (c) 2021 Gang Fan et al. This is an open access article distributed under the Creative Commons Attribution License, which permits unrestricted use, distribution, and reproduction in any medium, provided the original work is properly cited.

Seismicity sequence following a main earthquake usually contains much meaningful information for unveiling the focal mechanism and predicting the reoccurrence interval of large earthquakes. The spatiotemporal evolution of earthquakes before and after the 2008 Wenchuan earthquake $\left(M_{\mathrm{s}} 8.0\right)$ is analysed comprehensively in this study. The frequency-magnitude relation of the 3493 earthquake events retrieved from the database of the International Seismological Centre indicates that the adopted catalogue is complete for magnitudes $\geq M_{\mathrm{s}}$ 3.4. The seismicity during the 10 years before the Wenchuan earthquake remained stable, including the magnitudes and focal depths. However, seismicity attenuated sharply in the year following the Wenchuan earthquake, and the magnitude of earthquakes before the Wenchuan earthquake decreased gradually. The area of the seismogenic zone of the 2008 Wenchuan earthquake was smaller than the earthquake stricken area. The earthquakes that occurred in the Longmenshan fault area and adjacent area in the study period were mainly shallow earthquakes. The focal depths of earthquakes in the study area became stable gradually after the Wenchuan earthquake, mainly within the range from 10 to $16 \mathrm{~km}$. The earthquakes in the study area were mainly distributed with an along-dip distance of $0-20 \mathrm{~km}$, and the seismicity was distributed uniformly along the fault strike.

\section{Introduction}

The 12 May $2008 M_{\mathrm{s}} 8.0$ Wenchuan earthquake and the 20 April $2013 M_{\mathrm{s}} 7.0$ Lushan earthquake, which both occurred on the Longmenshan fault, caused great losses of human lives and to the economy. The Longmenshan fault is an active fault in southwest China [1]. Since the Wenchuan earthquake and the Lushan earthquake both occurred on the Longmenshan fault, the Longmenshan fault has received much attention in recent years. Historically, a total of 25 destructive earthquakes have been recorded in the Longmenshan fault area since 1169. Before the Wenchuan earthquake, studies on the Longmenshan fault mainly focused on the fault slip rates [2]. After the Wenchuan earthquake, studies on the Longmenshan fault mainly concentrated on the seismogenic process $[3,4]$, stress state $[5,6]$, coseismic surface rupture [7], kinematic characteristics [8-11], and deep tectonic environment [12-15] of the fault area. Liu et al. [16] and Yin et al. [17] analysed the spatiotemporal distribution of the early aftershocks following the Wenchuan earthquake. Wu et al. [18] performed a comprehensive detection of early aftershocks following the Lushan earthquake using events 2 days before and 3 days after the main shock. Huang et al. [19] and Fang et al. [20] also relocated the aftershocks of the 2008 Wenchuan and 2013 Lushan earthquakes. The existing studies unveiled the Longmenshan fault. However, the considered temporal scale is limited. The geologic structure of the Longmenshan fault and adjacent area is significantly complicated; therefore, more 
studies are needed to deepen the understanding of the destructive Longmenshan fault.

Large shallow earthquakes are generally followed by abundant seismicity that decays with time according to a power law, typically known as Omori's law [21]. The earthquake events with typical foreshock, main shock, and aftershock are the most promising type to achieve shortimpending prediction of strong earthquakes, so it has attracted much attention [22]. However, due to its rarity, the understanding of foreshock activity of this type of earthquake is still very shallow. Seismicity following a main earthquake carries useful information regarding the triggering mechanism of earthquakes [23-28]. In recent years, many studies have focused on the historical earthquake sequence, including the Landers earthquake [29, 30], the Chi-Chi earthquake [31], the mid-Niigata Prefecture earthquake [32], the Tohoku earthquake [33], and the Rigan earthquake [34]. These studies promoted the understanding of the focal mechanisms of large earthquakes and offered engineering geologists a reference for making seismic hazard maps.

In this study, earthquake records with a temporal scale from 1 January 1900 to 31 December 2017 are adopted to reveal the spatiotemporal evolution of earthquakes in the Longmenshan fault area and adjacent area. The aims are to obtain innovative findings on the focal mechanism of the fault and to provide meaningful information for earthquake disaster prevention and mitigation in the Longmenshan fault area and adjacent area.

\section{Geological Background of the Study Area}

Earthquake events are complex geological phenomenon, they mainly occurred on the fault belts and also can affect the adjacent fault belts. The destructive 2017 Jiuzhaigou earthquake occurred in the adjacent area of the Longmenshan fault area. For these two reasons, the study area was defined as a rectangle with longitude ranging from $102.101^{\circ} \mathrm{E}$ to $106.397^{\circ} \mathrm{E}$ and latitude ranging from $29.790^{\circ} \mathrm{N}$ to $33.365^{\circ} \mathrm{N}$, which covers the Longmenshan fault belt and adjacent area, as illustrated in Figure 1. The Longmenshan fault belt is approximately $500 \mathrm{~km}$ long and $30-50 \mathrm{~km}$ wide, striking north-northeast and dipping west to steep faults beneath. The Longmenshan fault area is the boundary tectonic belt between the Qinghai-Tibet Plateau and the South China block. The elevation of the eastern margin of the Tibetan Plateau rises steeply westward from $500 \mathrm{~m}$ to $4000 \mathrm{~m}$. The Longmenshan fault area has become active since the late Cenozoic. It is composed of three main faults with strong seismic capacities, i.e., the west Wenchuan-Maoxian Fault, the central Yingxiu-Beichuan Fault, and the east Guanxian-Jiangyou Fault. Among these faults, no rupture was found on the Wenchuan-Maoxian Fault during the Wenchuan earthquake. A rupture approximately $240 \mathrm{~km}$ long was detected on the YingxiuBeichuan Fault, which was the main surface rupture of the Wenchuan earthquake [35]. A rupture approximately $70 \mathrm{~km}$ long was observed on the Guanxian-Jiangyou Fault. The faulting geometry along the rupture appears to be complex. Focal mechanism analysis and GPS observation results show that the Longmenshan fault has vertical uplift and northeast horizontal movement relative to the Sichuan Basin [36].

The Wenchuan earthquake was attributed to the strain accumulated in the Longmenshan fault area and caused by the collision between the Indian and Eurasian Plates along the Himalayan front and the uplift of the Qinghai-Tibet Plateau [8]. The 2008 Wenchuan earthquake was followed by an abundant amount of seismicity, providing an opportunity to analyse the spatiotemporal evolution of seismicity and the triggering mechanisms of great earthquakes.

\section{Data and Completeness Analysis}

The study period is from 1 January 1900 to 31 December 2017. The adopted earthquake catalogue in this study was retrieved from the database of the International Seismological Centre (ISC, https://www.isc.ac.uk). The earthquake catalogue provided by the ISC includes 3493 events in the study area, with magnitude $M_{\mathrm{s}}$ ranging from 1.6 to 8.0. The earthquake distribution and magnitude included in the adopted catalogue are plotted in Figure 1.

The completeness analysis of the adopted earthquake catalogue is a fundamental issue for the study of earthquake sequences. It has long been observed that the sizes of any randomly chosen group of tectonic earthquakes adhere to an inverse power law magnitude-frequency distribution known as the Gutenberg-Richter distribution [37, 38]. The cumulative form of the Gutenberg-Richter relationship can be written as

$$
\ln n(M)=a-b \cdot M,
$$

where $n(M)$ is the cumulative number of earthquakes with magnitudes greater than or equal to $M, M$ is the earthquake magnitude, $a$ and $b$ are constants, and the surface wave magnitude $M_{\mathrm{s}}$ is used in this study.

The Gutenberg-Richter relationship has generally been regarded as universal. It is applicative globally, in smaller regions and on individual faults $[39,40]$. The completeness of seismicity can be quantitatively represented by the magnitude of completeness, i.e., $M_{c}$. Figure 2 is the Gutenberg-Richter plot of the cumulative number of events $N$ versus $M_{\mathrm{s}}$ for the earthquake catalogue adopted in this study, with $a=6.81$ and $b=0.90$. An obvious curvature is detected in Figure 2. The magnitude of completeness, $M_{c}$, can be defined as the magnitude at the maximum curvature [41]. According to its definition, $M_{\mathrm{c}}=3.4$ in this study, as illustrated in Figure 2. The linear representation of the Gutenberg-Richter relationship in the segment with magnitude $M_{\mathrm{s}} \geq 3.4$ indicates that the adopted earthquake catalogue is complete above magnitude $M_{s}$ 3.4. Numerous earthquake events are often missing in earthquake catalogues following large events due to a large number of events occurring in a short time interval and to the coda noise generated by the large events [42]. This absence may be the reason for the flatting of the curve for $M_{\mathrm{s}}<3.4$. A deviation is observed in the high-magnitude segment in Figure 2, which is due to the shortage of samples with high magnitude. 


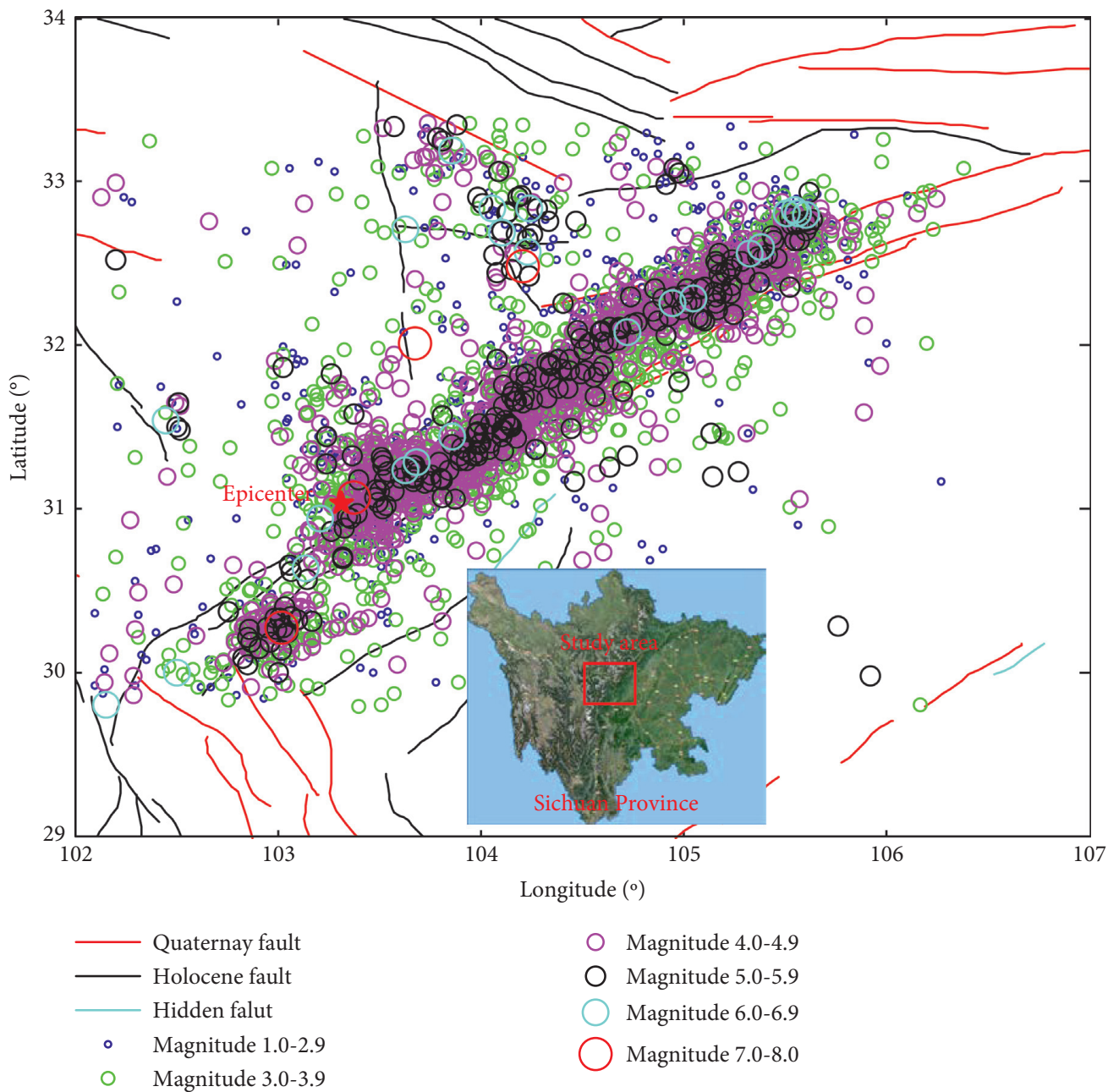

Figure 1: Earthquake distribution in the Longmenshan fault area and adjacent area. The scale and color of the circles represent the magnitude of earthquake events used in this study; the red star represents the epicentre of the 2008 Wenchuan earthquake.

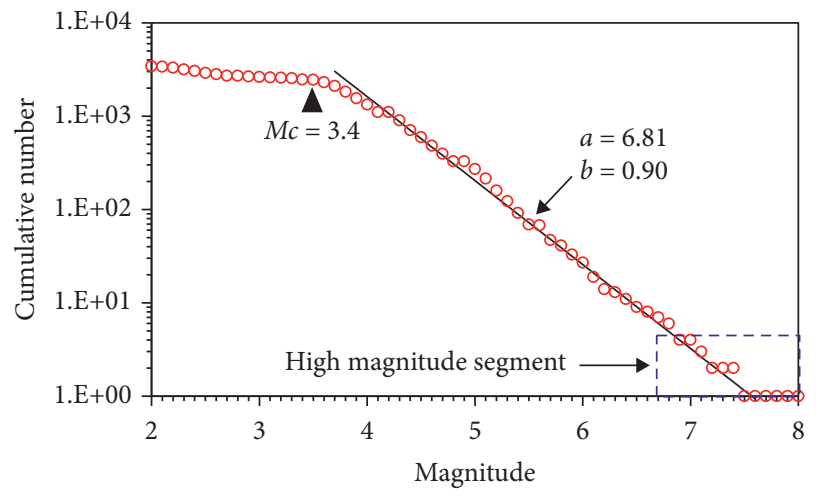

FIGURE 2: Gutenberg-Richter magnitude-frequency relationship from 1 January 1900 to 31 December 2017 in the Longmenshan fault area.

\section{Spatiotemporal Evolution Analysis}

In the past decade, two catastrophic earthquakes have occurred in the Longmenshan fault area and adjacent area, i.e., the 12 May 2008 Wenchuan earthquake $\left(M_{\mathrm{s}} 8.0\right)$ and the 20
April 2013 Lushan earthquake $\left(M_{\mathrm{s}}\right.$ 7.0). These two catastrophic earthquakes have some mechanical effects on the following seismicity in the study area $[43,44]$. Although the adopted catalogue includes earthquake events recorded from 1 January 1900 to 31 December 2017, this study mainly focuses on the spatiotemporal evolution of the earthquake events in approximately 10 years following the 2008 Wenchuan earthquake in the Longmenshan fault area and adjacent area, i.e., from 12 May 2008 to 31 December 2017.

4.1. Temporal Sequence. Not all following seismicity happens immediately following a main earthquake. Rather, the seismicity frequency decays like a diffusive process. According to the adopted catalogue of earthquake events, before the Wenchuan earthquake, the seismicity of the Longmenshan fault area and adjacent area was low. The slip rate of the Longmenshan fault, obtained by geologic observations and GPS, is very small (1-3 mm/a) [45]. In contrast, many earthquake events were recorded after the 2008 Wenchuan earthquake. The temporal distribution of the earthquake events in 20 years before (i.e., from 1 January 1988 to 11 May 2008) and 10 years after the 2008 Wenchuan 
earthquake (i.e., from 12 May 2008 to 31 December 2017) is plotted in Figure 3. Since the earthquake catalogue is incomplete below $M_{\mathrm{s}} 3.4$, only the earthquake records with $M_{\mathrm{s}}$ larger than 3.4 are plotted in Figure 3. To clearly present the historical earthquake events, only the earthquake events in the 20 years before the Wenchuan earthquake are plotted. In the near 20 years before the Wenchuan earthquake, the magnitudes of the earthquake events that occurred in the Longmenshan fault area and adjacent area were mainly less than $M_{s}$ 5.0. The moving average curve shows that the magnitudes of the earthquake events before the Wenchuan earthquake decreased gradually, while the seismicity in the 10 years before the Wenchuan earthquake remained stable. The magnitude of the earthquakes that occurred in the Longmenshan fault area and adjacent area in 2016 and 2017 increased obviously, as shown in Figure 3. The number of earthquake events with magnitudes exceeding $M_{\mathrm{s}} 5.0$ is limited, as shown in Figure 4. It can be found from Figure 4 that only 15 earthquake events with magnitudes of $M_{\mathrm{s}} 5$ or greater were recorded in the 20 years before the Wenchuan earthquake, and only 1 event with magnitude larger than 6 $\left(M_{\mathrm{s}}\right.$ 6.4) was recorded in this period. Then, the 2008 Wenchuan earthquake triggered an abundance of earthquakes in the Longmenshan fault area and adjacent area, including many earthquake events with magnitudes $M_{\mathrm{s}} \geq 5$.0. Figure 4 shows that a total of 1208 earthquakes with magnitude $M_{s} \geq 4.0$ and 226 earthquakes with magnitude $M_{\mathrm{s}} \geq 5.0$ were recorded in 10 years following the Wenchuan earthquake.

To clarify the temporal evolution of seismicity following the Wenchuan earthquake, the number of earthquakes $\left(M_{s} \geq 3.4\right)$ in each year and cumulative number are illustrated in Figure 5. Figure 5(a) shows that the number of earthquakes in 2009 is much smaller than that in 2008, implying a sudden attenuation of earthquakes. Then, the number of earthquakes decreases gradually from 2009 to 2012. Due to the occurrence of the 2013 Lushan earthquake, which was also located in the Longmenshan fault area, the number of earthquakes increased suddenly and then decreased gradually from 2013 to 2016 . The increase in the number in 2017 may have been due to the occurrence of the Jiuzhaigou earthquake $\left(M_{\mathrm{w}} 6.5\right)$, which occurred near the Longmenshan fault zone. In this study, the modified OmoriUstu formula $n(t)=K(t+c)^{-\mathrm{p}}$ was adopted to predict the attenuation of the seismicity of the 2008 Wenchuan earthquake [46]. Figure 5(b) shows that the Omori-Ustu law could predict the attenuation of seismicity approximately, and the deviation in 2013 was caused by the Lushan earthquake.

To reveal the seismogenic environment of the earthquake events in the Longmenshan fault area, the earthquake events in the study area in different periods were analysed. The analysis period (1 January 1900 to 31 December 2017) was divided into three stages: 1 January 1900 to 12 May 2008 Wenchuan earthquake, 12 May 2008 Wenchuan earthquake to 20 April 2013 Lushan earthquake, and 20 April 2013 Lushan earthquake to 31 December 2017. The earthquake events in these three stages are plotted in Figure 6. The earthquake events in the

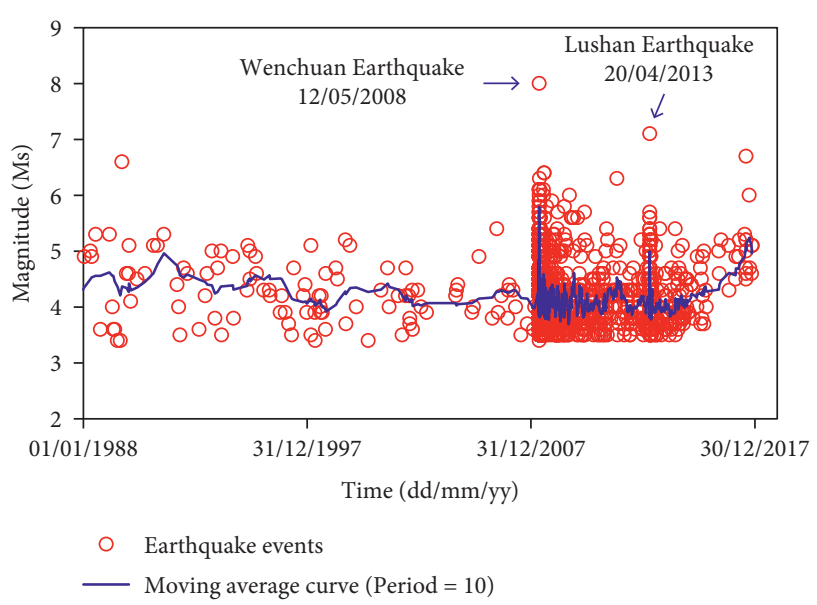

Figure 3: Temporal sequence of earthquake events $\left(M_{\mathrm{s}} \geq 3.4\right) 20$ years before and 10 years following the 2008 Wenchuan earthquake.

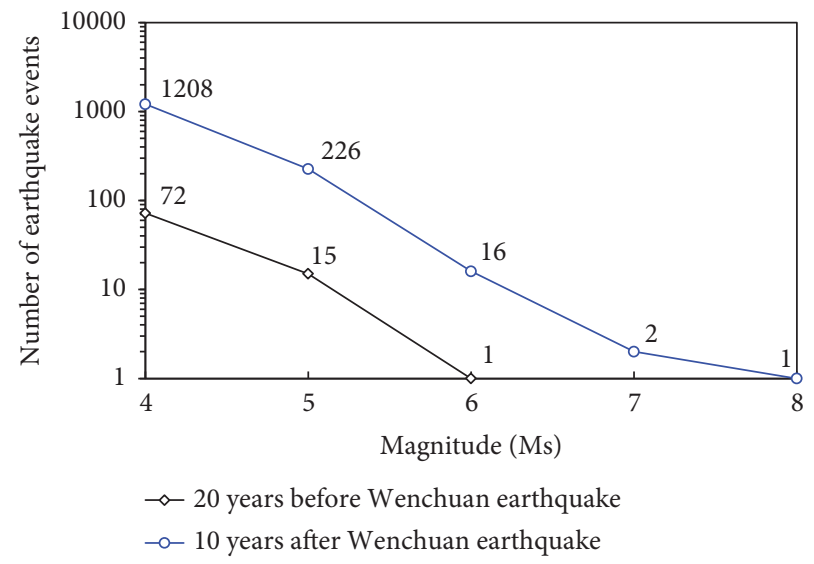

FIGURE 4: Number of earthquake events with magnitude not less than a certain value in 20 years before and 10 years following the 2008 Wenchuan earthquake. The numbers of earthquake events with magnitude not less than $M_{\mathrm{s}} 4,5,6,7$, and 8 are illustrated.

Longmenshan fault area and adjacent area in the study period were mainly distributed in three segments, i.e., the Lushan segment, Yingxiu segment, and BeichuanGuangyuan segment, as illustrated in Figure 6. Before the Wenchuan earthquake, there were many microearthquakes with magnitudes $M_{\mathrm{s}}<3.0$ in the Lushan segment and the Yingxiu segment. However, few earthquakes were recorded in the northeast Beichuan-Guangyuan segment, as illustrated in Figure 6(a). The northern section of the Longmenshan fault belt had almost no movement before 2007, and the shortening rate and the right-lateral slip rate were $0.2 \mathrm{~mm} / \mathrm{a}$ and $0.18 \mathrm{~mm} / \mathrm{a}$, respectively [36]. The movement of the south section of the Longmenshan fault was small, and the shortening rate and the right-lateral slip rate were $1.8 \mathrm{~mm} / \mathrm{a}$ and $1.6 \mathrm{~mm} / \mathrm{a}$, respectively [36]. These data indicate that the Yingxiu segment experienced intense extrusional strain dominated by fragmentation in the seismogenic period and that the Wenchuan earthquake was the result of rapid dislocation in the Yingxiu segment of the Longmenshan fault. 


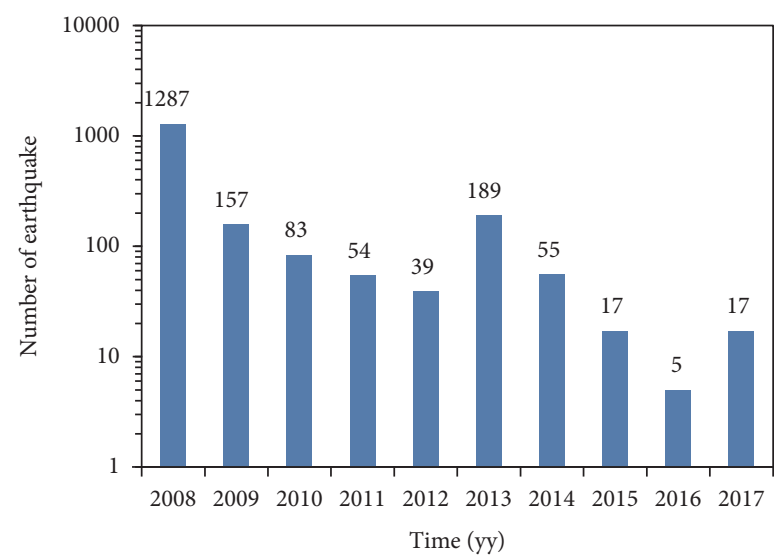

(a)

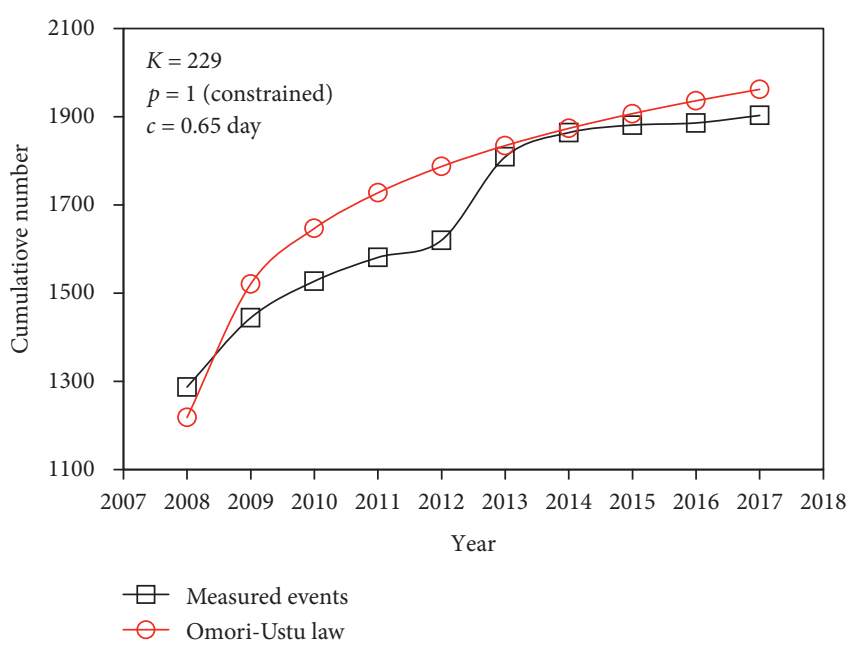

(b)

Figure 5: Attenuation of seismicity sequence: (a) number of earthquakes $\left(M_{\mathrm{s}} \geq 3.4\right)$ in each year after the 2008 Wenchuan earthquake, and (b) cumulative number of earthquakes.

When the Wenchuan earthquake occurred in 2008, the seismicity extended to the Beichuan-Guangyuan segment immediately, and a number of earthquakes were recorded in the Beichuan-Guangyuan segment, including many earthquakes with magnitude $M_{\mathrm{s}}>4.0$. Nevertheless, the seismicity did not extend to the Lushan segment, and the seismic density in the Lushan segment did not change very much before and after the Wenchuan earthquake, as shown in Figure 6(b). A comparison of Figures 6(a) and 6(b) implies that the area of the seismogenic zone of the Wenchuan earthquake was smaller than the earthquake stricken area, denoting that, in the rapid rupture process of a seismogenic fault, other seismogenic faults can connect and expand to form a larger catastrophic fault. The seismogenic zone is the depth interval of unstable (stick-slip) behavior where earthquakes can nucleate and slip coseismically.

When the Lushan earthquake occurred in 2013, the seismicity in the Lushan segment was activated, and many seismicity events were recorded in this segment between 20 April 2013 and 31 December 2017, as illustrated in Figure 6(c). To reveal the influence of the Lushan earthquake on the seismicity in the Lushan segment, the seismicity distributions for one year before and one year following the Lushan earthquake are illustrated in Figure 7. Figure 7 shows that only two earthquake events were recorded in the Lushan segment one year before the Lushan earthquake. However, many earthquake events were recorded in the Lushan segment one year following the Lushan earthquake. By comparing the seismic density in the study area one year before and one year following the 2013 Lushan earthquake, it could be found that the seismic density in the Longmenshan fault area increased slightly due to the Lushan earthquake, as shown in Figures 7(a) and 7(b). The number of earthquakes with magnitudes $M_{\mathrm{s}}$ 3.0-3.9 clearly increased. The Lushan earthquake motivated stress release in the Yingxiu segment and the Beichuan-Guangyuan segment, leading to an increase in seismic density in these two segments.
The distribution of the seismicity of the Wenchuan earthquake indicates an asymmetric bilateral rupture of the Longmenshan fault and adjacent area. The rupture extended to the northeast immediately after the Wenchuan earthquake, and the rupture was hindered to the southwest due to a blocking body. The delayed rupture of the blocking body triggered the 2013 Lushan earthquake, as illustrated in Figure 6(c), and increased the seismicity in the Yingxiu segment and the Beichuan-Guangyuan segment slightly, as illustrated in Figure 7.

4.2. Attenuation of Seismicity. The seismicity number decays over time, depending on several parameters peculiar to each seismogenic region, including main shock magnitude, crustal rheology, and stress changes along the fault. However, the exact roles of these parameters in controlling the duration of the earthquake sequence are still unknown [24]. The fast decay of seismicity following large earthquakes has been widely reported by researchers. The attenuations of seismicity of the Wenchuan earthquake and the Lushan earthquake are compared in Figure 8, although the relationship between the Wenchuan earthquake and the Lushan earthquake is still a controversial topic. Figure 8 shows that the number of seismicity events of the Wenchuan earthquake is much larger than that of the Lushan earthquake. In the first month following the Wenchuan earthquake, nearly 1179 earthquakes with magnitudes $M_{\mathrm{s}} \geq 3.4$ were recorded. However, only 179 earthquakes with magnitude $M_{s} \geq 3.4$ were recorded in the first month following the Lushan earthquake. The number of earthquake events of the Wenchuan earthquake with magnitude $M_{s} \geq 5.0$ (109 recorded events) is also much larger than that of the Lushan earthquake (20 recorded events) in the first month. Figure 8 also shows that the earthquakes attenuated quickly after the main shocks of the Wenchuan and Lushan earthquakes. Two months after the main shocks of the Wenchuan earthquake 


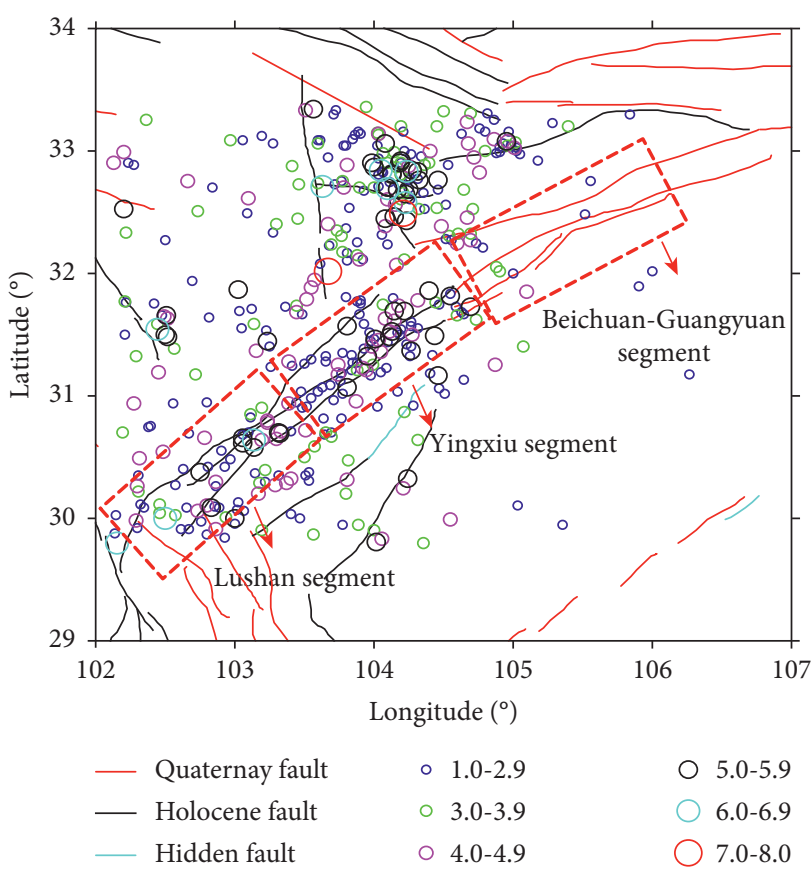

(a)

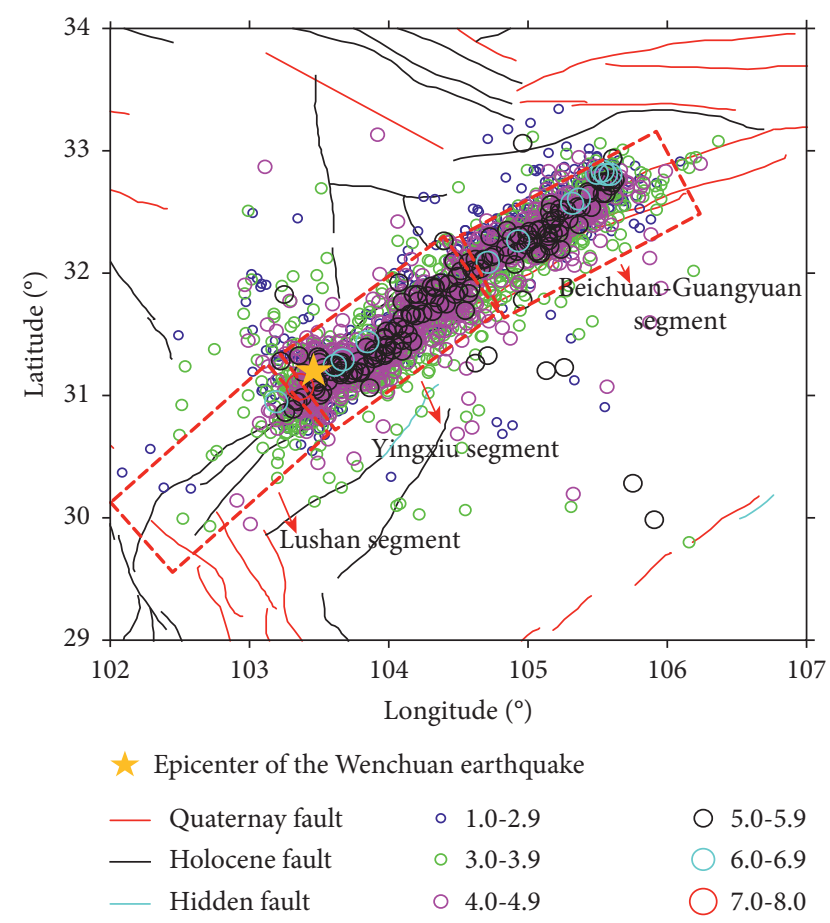

(b)

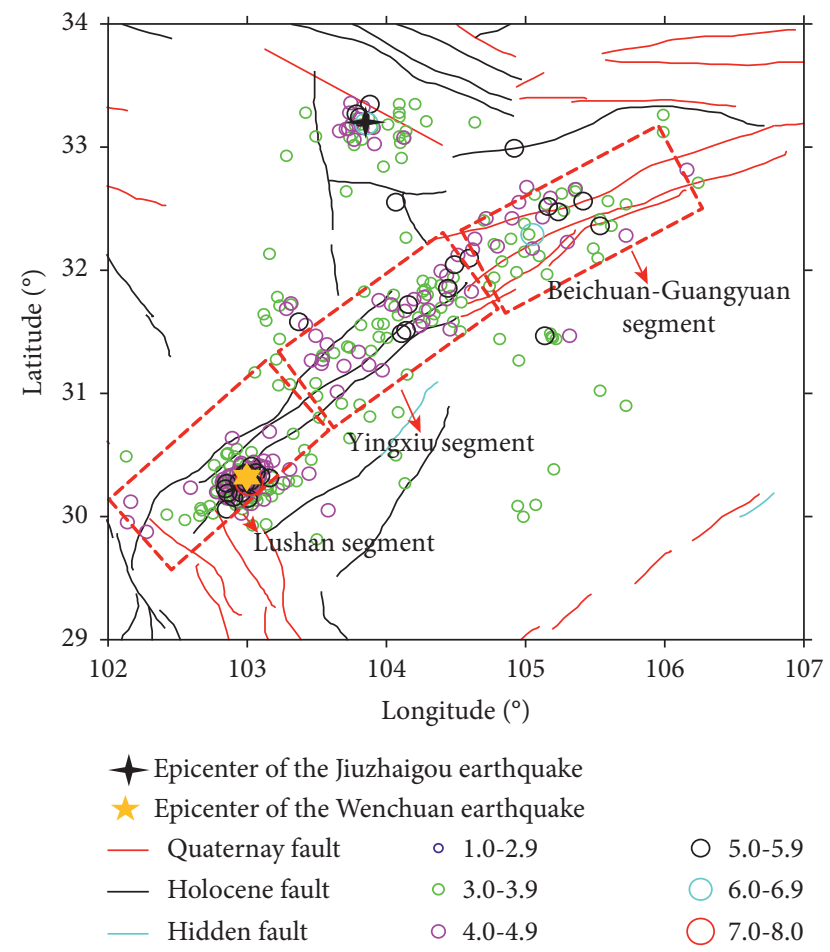

(c)

FIGURE 6: Earthquake catalog in the Longmenshan fault area and adjacent area. (a) From 1 January 1900 to 12 May 2008 Wenchuan earthquake, (b) from 12 May 2008 Wenchuan earthquake to 20 April 2013 Lushan earthquake, and (c) from 20 April 2013 Lushan earthquake to 31 December 2017.

and the Lushan earthquake, the number of earthquakes decreased sharply and then became stable gradually. One year after the main shocks of the Wenchuan and Lushan earthquakes, the seismicity was extremely low, and no earthquake with magnitude $M_{\mathrm{s}} \geq 5.0$ occurred in the Longmenshan fault area. The reported fast decay of the seismicity following the Wenchuan earthquake is in accordance with the 1999 earthquake and the 2011 Tohoku earthquake [31, 33]. 


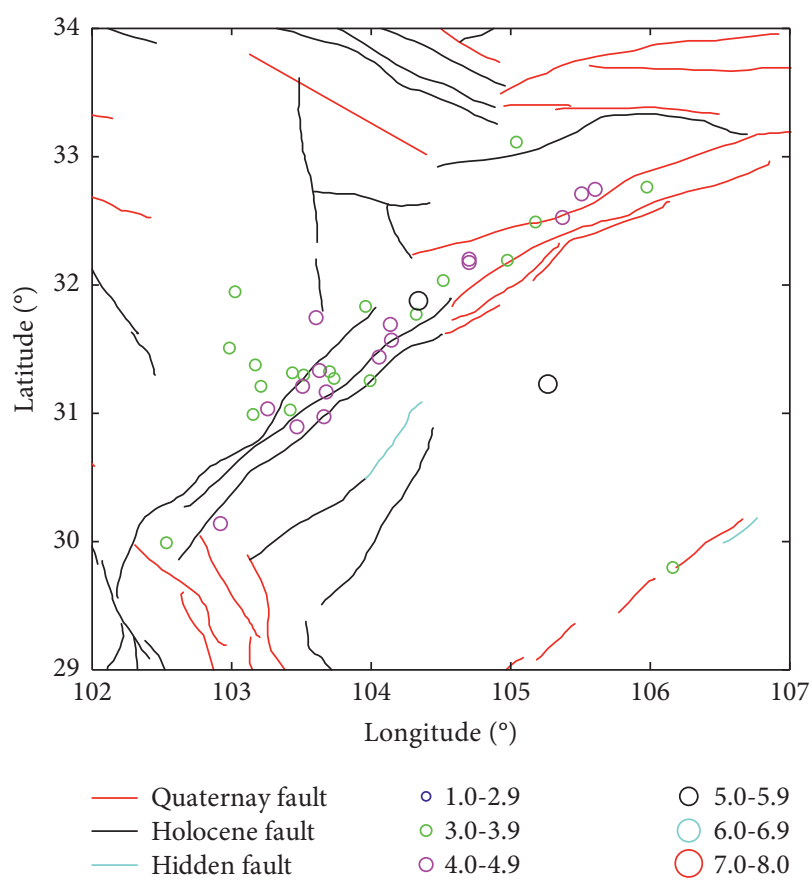

(a)

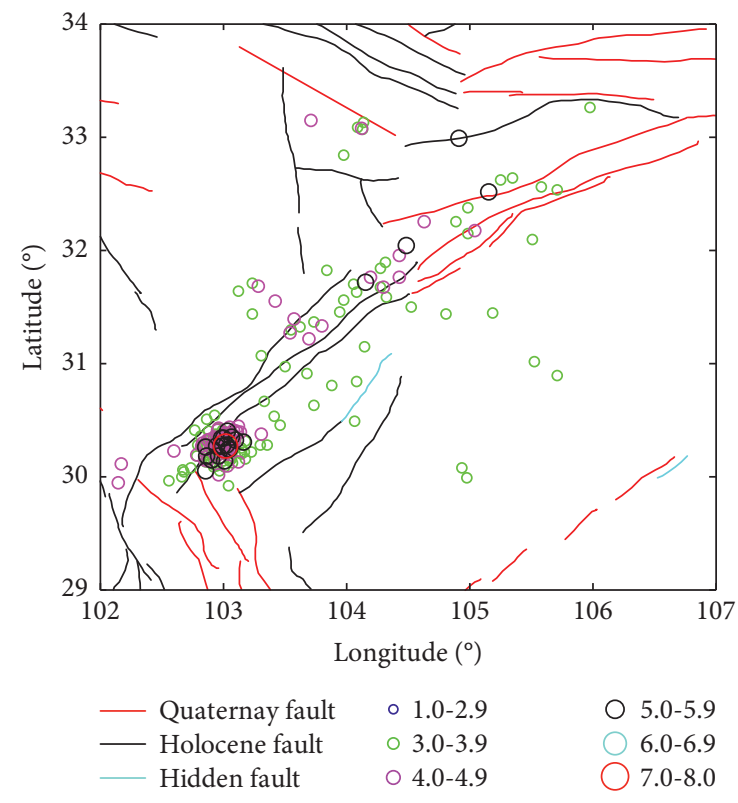

(b)

FIgURE 7: Seismicity distribution in one year. (a) Before the Lushan earthquake and (b) one year following the Lushan earthquake.

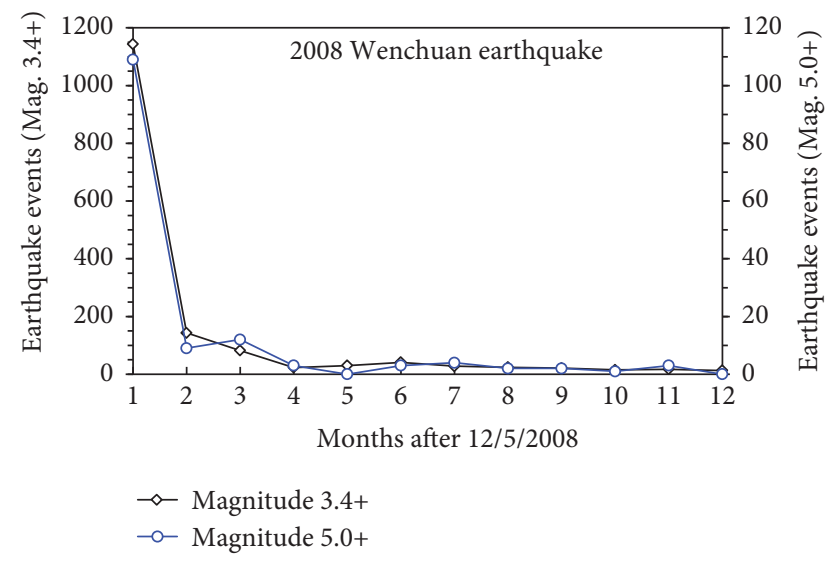

(a)

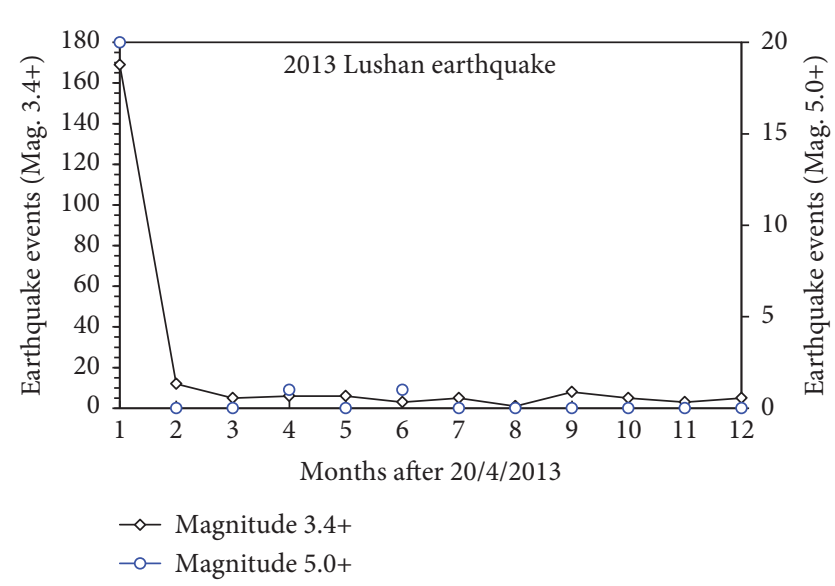

(b)

Figure 8: Number of seismicity events with magnitude $\left(M_{\mathrm{s}}\right)$ not less than 3.4 and 5.0 in one year following (a) the 2008 Wenchuan earthquake and (b) one year following the 2013 Lushan earthquake. Magnitude 3.4+ and magnitude 5.0+ represent magnitude not less than $M_{\mathrm{s}} 3.4$ and $M_{\mathrm{s}} 5.0$, respectively.

4.3. Focal Depth. Focal depth is one of key parameters for earthquake early warning; combined with the crustal velocity model of the fault belt, the focal depth can provide meaningful information for earthquake early warning. Focal depth analysis can be used to unveil the spatial characteristics of the fault belt and the mechanism of great earthquakes in the Longmenshan fault area. In this study, the focal depth of earthquakes before the Wenchuan earthquake during the 10 years before the Wenchuan earthquake and the seismicity during the 10 years following the Wenchuan earthquake are analysed separately, as shown in Figure 9.
This figure implies that the earthquakes that occurred in the Longmenshan fault area and the adjacent area in the past 20 years were mainly shallow earthquakes. Almost all the earthquake events occurred at depths less than $60 \mathrm{~km}$. Figure 9(a) shows that the focal depth of the earthquakes in the study area before the Wenchuan earthquake remained stable in the 10 years before the Wenchuan earthquake, mainly changing in the range of $10-30 \mathrm{~km}$. In the 6 months following the Wenchuan earthquake, the focal depth of the seismicity fluctuated dramatically within the depth range of 0-30 km. An abundance of seismicity occurred at shallow 
focal depths above $10 \mathrm{~km}$. The moving average curve shows that the focal depth of the seismicity became stable gradually in the period before the Lushan earthquake (i.e., from 12 May 2008 to 20 April 2013), mainly within the depth range of $10-16 \mathrm{~km}$. When the Lushan earthquake occurred on 20 April 2013, the moving average curve suffered a sudden fluctuation and then became stable quickly. As time passed, the focal depths of the seismicity became stable gradually. It should be pointed out that despite the uncertainties of focal depth of the earthquakes in the ISC catalog, many researchers have paid attention to the identification of focal depth, and the identification accuracy of focal depth has been improved $[47,48]$. The uncertainty of focal depth in the ISC catalog remains indistinct; however, with the increasing accuracy of interpretation on focal depth, a better understanding and application of focal depth can be expected.

4.4. Along-Dip and Along-Strike Evolution of Seismicity. The along-dip and along-strike evolution of seismicity are analysed in this study to reveal the spatiotemporal distribution of seismicity in the study area. The directional study of seismicity can help engineering geologists unveil the distribution characteristics of earthquake-induced landslides. The Gaussian projection is adopted to locate the epicentres of the earthquake events in plane coordinates before the analysis. Here, the along-dip distance is defined as the perpendicular distance from the epicentre of each earthquake to the central Yingxiu-Beichuan Fault. The along-strike distance is defined as the perpendicular distance from the epicentre of each earthquake to the normal line, which crosses though the epicentre of the Wenchuan earthquake on the central Yingxiu-Beichuan Fault. One limitation of this analysis is that we simply assign the location from the recorded catalogue; in reality, the true locations of the earthquake events could be different $[5,49]$. Because this study mainly focuses on the overall evolution of seismicity following the Wenchuan main shock, such a difference should not produce any crucial bias to the overall conclusion of this study.

The temporal distribution of seismicity versus along-dip distance in the 10 years following the Wenchuan earthquake is illustrated in Figure 10. The seismicity mainly occurred in the area with along-dip distances less than $20 \mathrm{~km}$. The range of the along-dip distance increased gradually with time. Postearthquake investigations show that more than $70 \%$ of the landslides triggered by the Wenchuan earthquake were located within $3 \mathrm{~km}$ from seismic faults and $80 \%$ within $5 \mathrm{~km}$ [50]. Hence, the spatiotemporal evolutions of seismicity within along-dip distances of $0-3 \mathrm{~km}$ and $0-5 \mathrm{~km}$ are detected in this study. In addition, since Figure 10 indicates that the earthquakes are mainly distributed in the area with along-dip distances less than $20 \mathrm{~km}$, the spatiotemporal evolutions within $0-10 \mathrm{~km}$ and $0-20 \mathrm{~km}$ are also analysed. The earthquakes with magnitude $M_{\mathrm{s}} 3.4$ to 5.0 and magnitude $M_{\mathrm{s}} 5.0$ to 8.0 are analysed separately, as illustrated in Figures 11 and 12, respectively.

It is clear that, within the along-dip distances of $0-3 \mathrm{~km}$, $0-5 \mathrm{~km}$, and $0-10 \mathrm{~km}$, the earthquake events in the study area with magnitude $M_{\mathrm{s}} 3.4$ to 5.0 and $M_{\mathrm{s}} 5.0$ to 8.0 are distributed uniformly along the distance, as shown in Figures 11(a)-11(c) and 12(a)-12(c). However, Figures $11(\mathrm{~d})$ and $12(\mathrm{~d})$ show that when the along-dip distance exceeds $10 \mathrm{~km}$, the seismic density of seismicity decreases gradually with increasing along-dip distance. The seismic density with an along-dip distance of $0-10 \mathrm{~km}$ is larger than that with an along-dip distance of $10-20 \mathrm{~km}$. Figure 11 also shows that the seismicity with small magnitudes (green circles and light green circles in Figure 11) mainly occurred 100 days after the main shock of the Wenchuan earthquake. The earthquakes with magnitudes $M_{s} 4.0$ to 5.0 (the red circles and light red circles in Figure 11) occurred uniformly with a logarithmic time scale as time passed in the 10 years after the Wenchuan earthquake. Figure 12 shows that the earthquakes with magnitudes of $M_{s}$ 5.0 to 8.0 are also distributed uniformly with a logarithmic time scale in the 10 years following the Wenchuan earthquake.

The above analysis indicates that the earthquakes of the Wenchuan earthquake were mainly distributed with alongdip distances of $0-20 \mathrm{~km}$, and the earthquakes occurred uniformly with a logarithmic time scale in the 10 years following the Wenchuan earthquake.

The Longmenshan fault is a banded fault, and most of the earthquakes after the Wenchuan earthquake in the study area occurred along the fault strike. Hence, the study on the along-strike distance of earthquakes is more meaningful than the relative distance between the earthquakes and the epicentre of the main shock of the Wenchuan earthquake. The spatiotemporal evolution of earthquakes along the fault strike is illustrated in Figure 13. It shows that the earthquakes in the study area are distributed uniformly along the fault strike, which can also be found in Figure 1. The length of the Longmenshan fault is approximately $240 \mathrm{~km}$. In the study area, the farthest earthquake event along the fault strike is approximately $250 \mathrm{~km}$ from the epicentre of the Wenchuan earthquake.

The surface rupture of Wenchuan earthquake near the epicentre mainly extended towards the northeast direction and did not extend towards the southwest direction. The 2013 Lushan earthquake occurred on the south segment of the Longmenshan fault belt, the epicentre of which is approximately $87 \mathrm{~km}$ from the epicentre of the Wenchuan earthquake. A seismic gap approximately $45 \mathrm{~km}$ long was observed between the Lushan earthquake and the Wenchuan earthquake. However, earthquake-generated stress changes may enhance the tectonic load applied to another fault, moving it closer to failure [29]. Hence, the 2008 Wenchuan earthquake may have motivated the occurrence of the 2013 Lushan earthquake $[43,51,52]$.

\section{Discussion}

This study shows that the earthquake sequence of the Wenchuan earthquake has not ended and that the seismicity will continue for years. The relationship between the Wenchuan earthquake and the Lushan earthquake is still under debate $[41,46,48]$. 


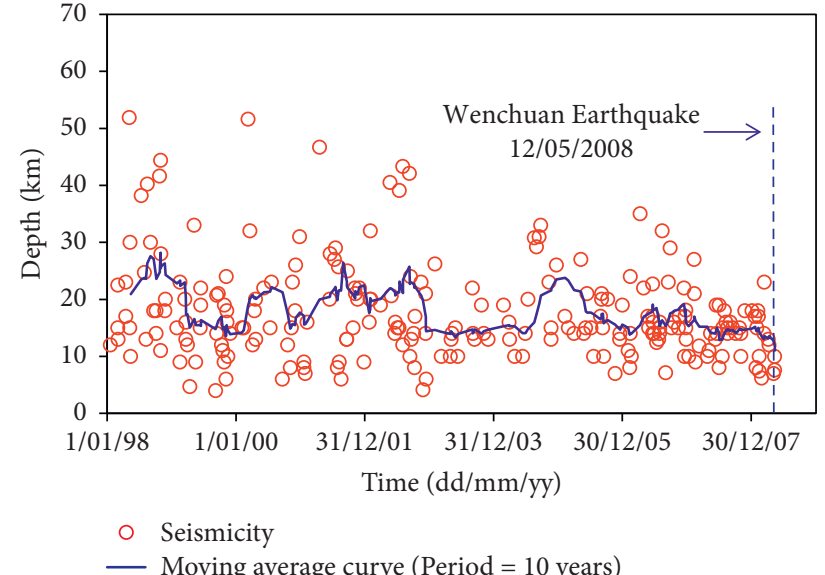

- Moving average curve (Period $=10$ years)

(a)

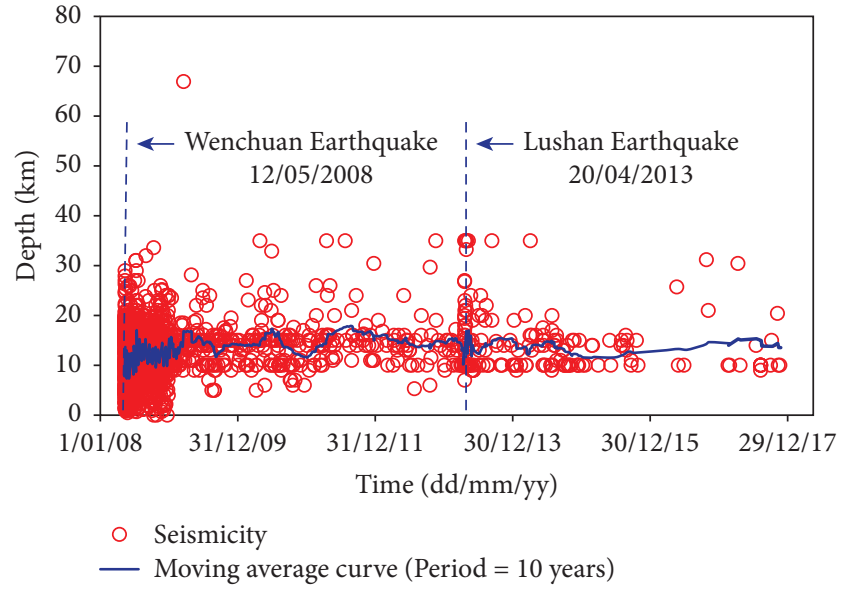

(b)

Figure 9: Focal depth of (a) earthquakes in 10 years before the Wenchuan earthquake and (b) earthquakes in 10 years following the 2008 Wenchuan earthquake in the Longmenshan fault area.

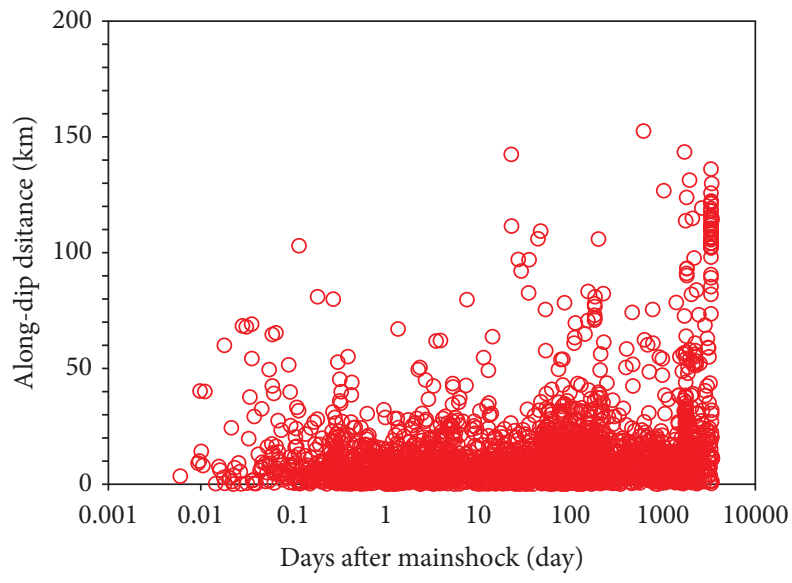

FIGURE 10: Distribution of seismicity with along-dip distance in 10 years following the Wenchuan earthquake.

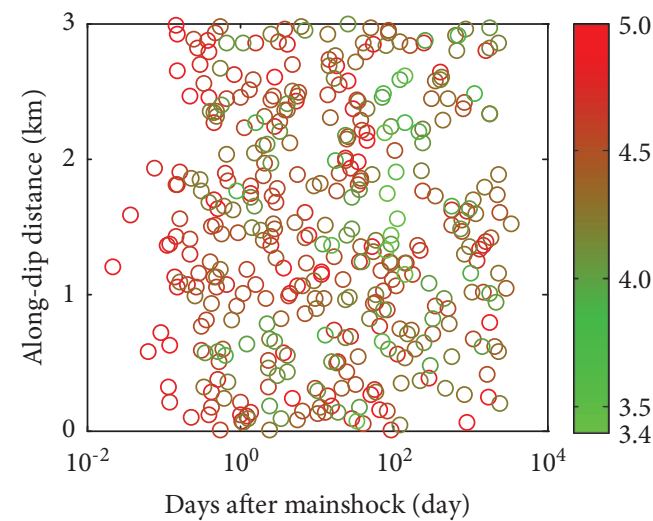

(a)

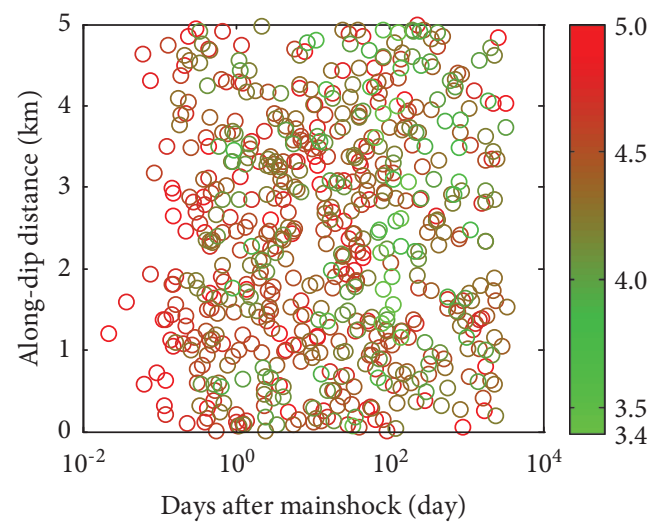

(b)

Figure 11: Continued. 


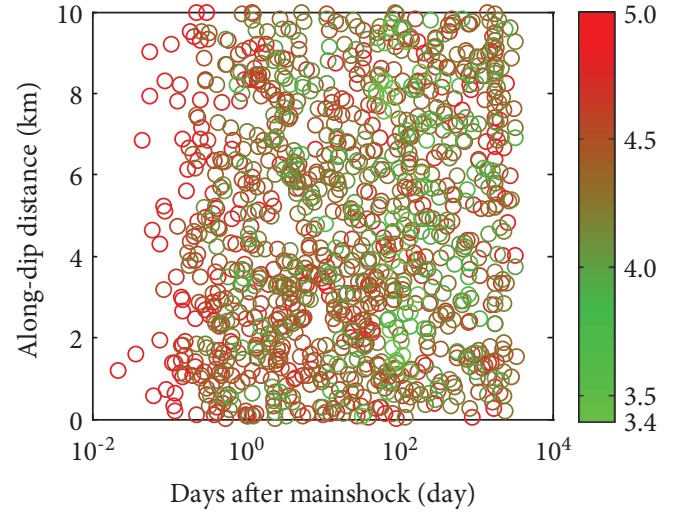

(c)

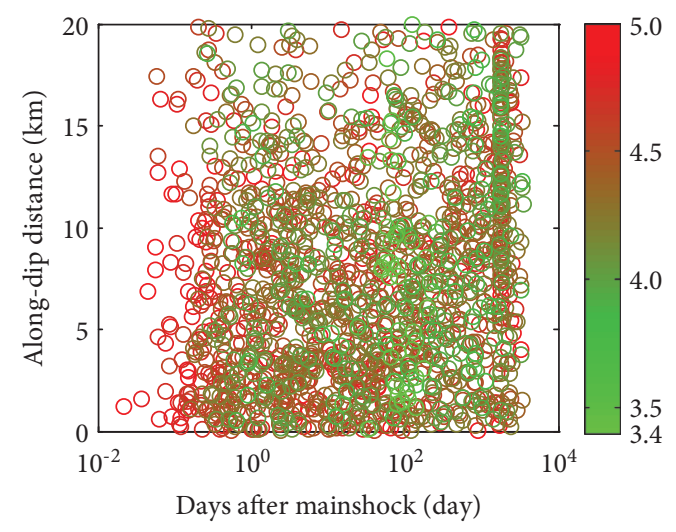

(d)

FIGURE 11: Spatiotemporal evolution of seismicity with magnitude $M_{\mathrm{s}} 3.4$ to 5.0 along the fault dip with logarithmic time since the main shock, projection within (a) $3 \mathrm{~km}$, (b) $5 \mathrm{~km}$, (c) $10 \mathrm{~km}$, and (d) $20 \mathrm{~km}$ of the perpendicular to strike distance. The colors of the circles represent the magnitude of earthquake events.

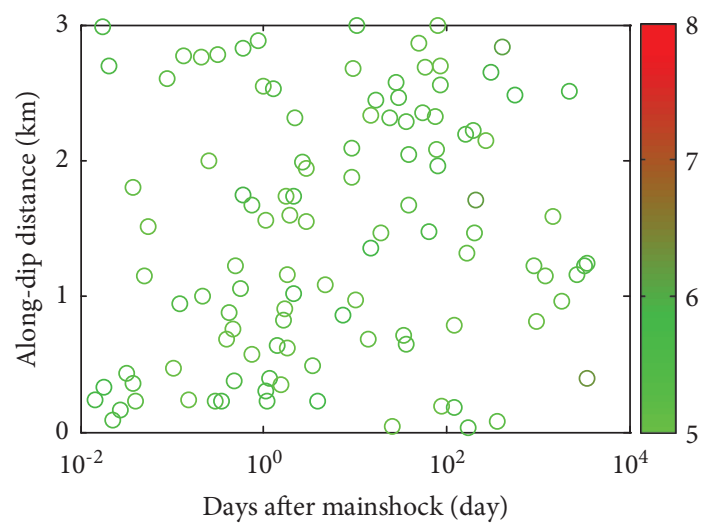

(a)

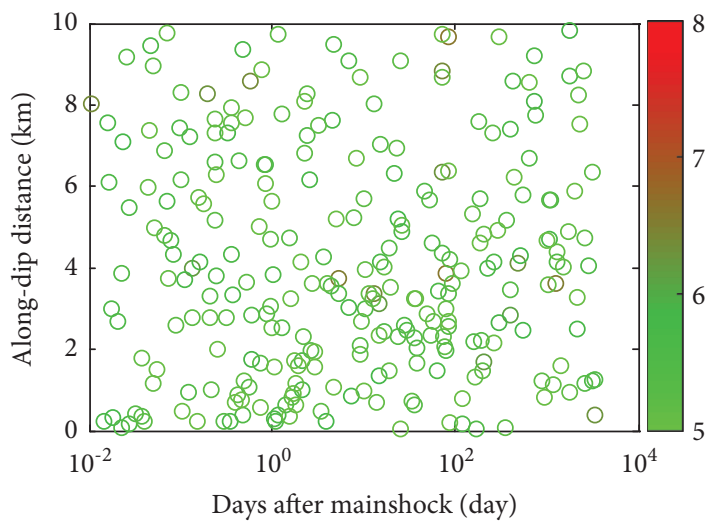

(c)

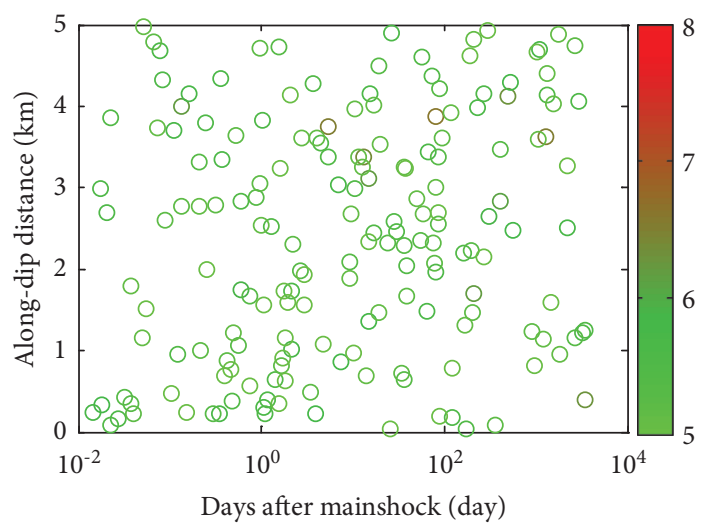

(b)

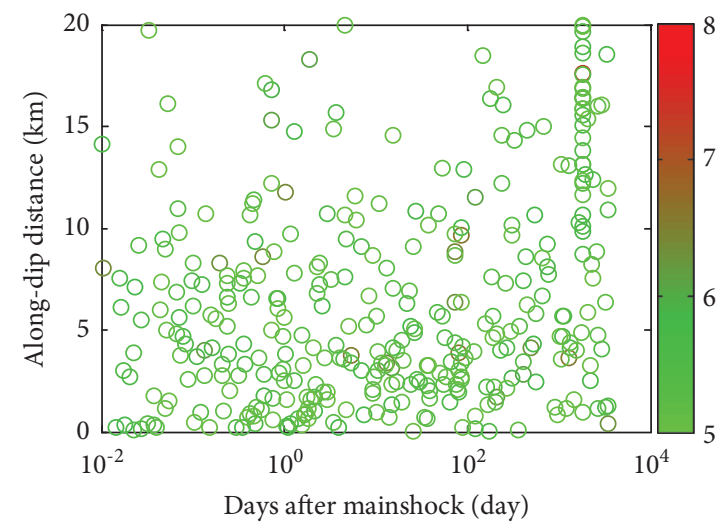

(d)

FIGURE 12: Spatiotemporal evolution of seismicity with magnitude $M_{\mathrm{s}} 5.0$ to 8.0 along the fault dip with logarithmic time since the main shock; projection within (a) $3 \mathrm{~km}$, (b) $5 \mathrm{~km}$, (c) $10 \mathrm{~km}$, and (d) $20 \mathrm{~km}$ of the perpendicular to strike distance. The colors of the circles represent the magnitude of earthquake events.

The occurrence of the next strong earthquake in the Longmenshan fault belt and adjacent area is of great concern to many scientists and millions of Chinese people. The Wenchuan earthquake now marks a new beginning for strain to build up for another great earthquake caused by dextral-slip thrust offset in the Longmenshan Mountains [48]. Studies have been conducted on the prediction of recurrence interval in the Longmenshan fault belt. The recurrence interval is estimated to be 3000-6000 years by offset landforms, 5000-5500 years by earthquake moment rate, 


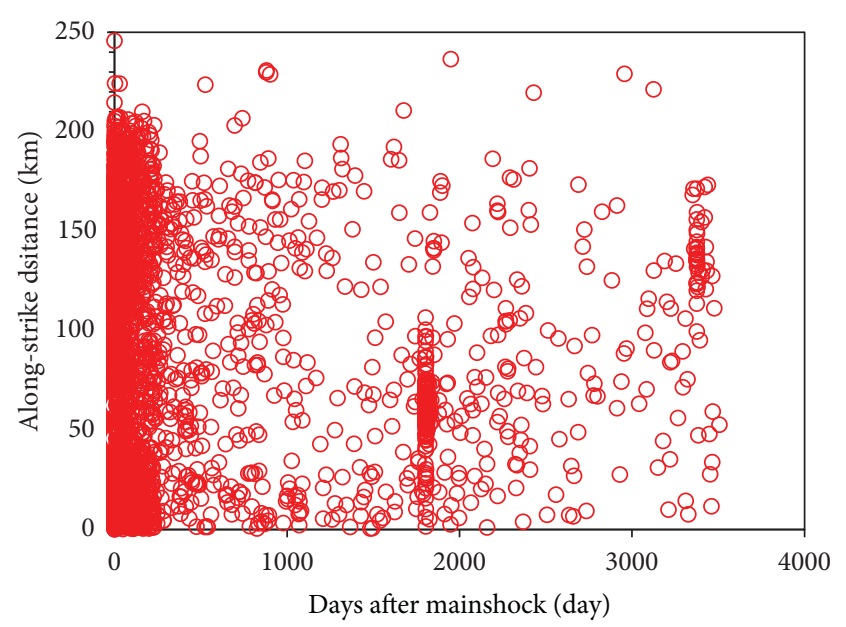

FIGURE 13: Spatiotemporal evolution of seismicity occurred in the Longmenshan fault area along the fault strike with logarithmic time since in 10 years following the main shock of the Wenchuan earthquake.

and 2600-3800 years by fault slip rate [52]. A study in an exploratory trench before the Wenchuan earthquake indicated that the strong earthquake recurrence interval of a single fault in the Longmenshan fault belt was estimated to be 2000-3000 years. The seismic wave inversion and GPS rate after the Wenchuan earthquake indicate that the average recurrence interval of strong earthquakes with magnitude $M_{\mathrm{s}}=8.0$ is $2000-10000$ years [45]. The matter of multiple faults being involved and the inadequacies of measurements in the region lead to a wide range in calculation results.

It should be noted that the Lushan earthquake is located at the Y-shaped intersection point of the northeast Longmenshan fault belt, northwest Xianshuihe Fault belt, and north-south Anninghe Fault belt. The Lushan earthquake is the largest earthquake since the Wenchuan earthquake in this area. The occurrence of the Lushan earthquake may directly lead the underground stress condition change and ground surface ruptures in the Xianshuihe Fault belt and the Anninghe Fault belt, as well as in the rupture blank zone between the epicentres of the Wenchuan earthquake and the Lushan earthquake, as illustrated in Figure 1. Attention should be paid to the stress change in these areas, and more studies should be conducted in the future. Underground stress observation techniques, which do not depend on seismic records, can be a meaningful method for earthquake disaster mitigation in this area.

\section{Conclusions}

The spatiotemporal evolution of earthquakes in Longmenshan fault and adjacent area is analysed in this study. Several main conclusions can be drawn:

(1) The earthquake activity over the 10 years before the Wenchuan earthquake remained stable, the seismicity attenuated suddenly in the first year following the main shock, and the magnitude of earthquakes before the Wenchuan earthquake decreased gradually thereafter.
(2) The seismogenic zone of the Wenchuan earthquake was smaller than the earthquake stricken area.

(3) The earthquakes that occurred in the Longmenshan fault area and adjacent area in the study period were mainly shallow earthquakes, with focal depths of less than $60 \mathrm{~km}$.

(4) In the 6 months following the Wenchuan earthquake, the focal depths of the earthquakes fluctuated dramatically within the range from 0 to $30 \mathrm{~km}$ and then gradually stabilized, mainly within the range from 10 to $16 \mathrm{~km}$.

(5) The earthquakes in the study area mainly distributed with an along-dip distance of $0-20 \mathrm{~km}$, and the earthquakes occurred uniformly over a logarithmic time scale during the 10 years following the Wenchuan earthquake. The earthquakes were distributed uniformly along the fault strike.

\section{Data Availability}

The test data used to support the findings of this study are included within the article.

\section{Conflicts of Interest}

The authors declare that there are no conflicts of interest regarding the publication of this paper.

\section{Acknowledgments}

This research was financially supported by the National Natural Science Foundation of China (No. 41907247) and the Open Fund of State Key Laboratory of Geohazard Prevention and Geoenvironment (No. SKLGP2021K008).

\section{References}

[1] P.-Z. Zhang, "Beware of slowly slipping faults," Nature Geoscience, vol. 6, no. 5, pp. 323-324, 2013.

[2] R. J. Zhou, Y. Li, A. L. Densmore et al., "Active tectonics of the Longmen Shan region on the eastern margin of the Tibetan Plateau," Acta Geologica Sinica-English Edition, vol. 81, pp. 593-604, 2007.

[3] S. P. Pei, H. J. Zhang, J. R. Su, and Z. X. Cui, "Ductile gap between the Wenchuan and Lushan earthquakes revealed from the two-dimensional Pg seismic tomography," Scientific Reports, vol. 4, Article ID 6489, 2017.

[4] S. Toda, J. Lin, M. Meghraou, and R. S. Stein, “12 May 2008 $M=7.9$ Wenchuan, China, earthquake calculated to increase failure stress and seismicity rate on three major fault systems," Geophysical Research Letters, vol. 35, Article ID L17305, 2008.

[5] Z. Peng and P. Zhao, "Migration of early aftershocks following the 2004 Parkfield earthquake," Nature Geoscience, vol. 2, no. 12, pp. 877-881, 2009.

[6] X. Qin, Q. Chen, M. Wu, C. Tan, C. Feng, and W. Meng, "Insitu stress measurements along the Beichuan-Yingxiu fault after the Wenchuan earthquake," Engineering Geology, vol. 194, pp. 114-122, 2015.

[7] Y. Zhang, J. Shi, P. Sun et al., "Surface ruptures induced by the Wenchuan earthquake: their influence widths and safety 
distances for construction sites," Engineering Geology, vol. 166, pp. 245-254, 2013.

[8] C. B. Hu, Y. E. Cai, and Z. M. Wang, "Effects of large historical earthquakes, viscous relaxation, and tectonic loading on the 2008 Wenchuan earthquake," Journal of Geophysical Research, vol. 117, Article ID B06410, 2012.

[9] X. Fan, C. H. Juang, J. Wasowski et al., "What we have learned from the 2008 Wenchuan Earthquake and its aftermath: a decade of research and challenges," Engineering Geology, vol. 241, pp. 25-32, 2018.

[10] H. W. Wang, Y. F. Ren, and R. Z. Wen, "Source parameters, path attenuation and site effects from strong-motion recordings of the Wenchuan aftershocks (2008-2013) using a non-parametric generalized inversion technique," Geophysical Journal International, vol. 212, pp. 872-890, 2016.

[11] S. Zhang, Z. Wu, and C. Jiang, "Signature of fault healing in an aftershock sequence? The 2008 wenchuan earthquake," Pure and Applied Geophysics, vol. 173, no. 1, pp. 73-84, 2016.

[12] X. Lin, D. Dreger, H. Ge et al., "Spatial and temporal variations in the moment tensor solutions of the 2008 Wenchuan earthquake aftershocks and their tectonic implications," Tectonics, vol. 37, pp. 989-1005, 2018.

[13] C. Wang, C. Song, Q. Guo, J. Mao, and Y. Zhang, "New insights into stress changes before and after the Wenchuan Earthquake using hydraulic fracturing measurements," Engineering Geology, vol. 194, pp. 98-113, 2015.

[14] K. G. Zhu, C. Q. Chi, Z. N. Yu et al., "Extracting borehole strain precursors associated with the Lushan earthquake through principal component analysis," Annals of Geophysics, vol. 61, Article ID SE447, 2018.

[15] P. Xiong, X. H. Shen, X. F. Gu et al., "Seismic infrared anomalies detection in the case of the Wenchuan earthquake using bi-angular advanced along-track scanning radiometer data," Annals of Geophysics, vol. 58, Article ID S0217, 2015.

[16] Y. Liu, T. Chen, F. Xie et al., "Analysis of fluid induced aftershocks following the 2008 Wenchuan Ms 8.0 earthquake," Tectonophysics, vol. 619-620, pp. 149-158, 2014.

[17] X. Z. Yin, J. H. Chen, Z. Peng et al., "Evolution and distribution of the early aftershocks following the $2008 \mathrm{Mw} 7.9$ wenchuan earthquake in sichuan, China," Journal of Geophysical Research: Solid Earth, vol. 123, no. 9, pp. 7775-7790, 2018.

[18] J. Wu, D. Yao, X. Meng, Z. Peng, J. Su, and F. Long, "Spatialtemporal evolutions of early aftershocks following the 2013 Mw 6.6 Lushan earthquake in Sichuan, China," Journal of Geophysical Research: Solid Earth, vol. 122, no. 4, pp. 28732889, 2017.

[19] Y. Huang, J. Wu, T. Zhang, and D. Zhang, "Relocation of the M8.0 Wenchuan earthquake and its aftershock sequence," Science in China-Series D: Earth Sciences, vol. 51, no. 12, pp. 1703-1711, 2008.

[20] L. J. Fang, W. Wu, W. Wang et al., "Relocation of the mainshock and aftershock sequences of Ms 7.0 Sichuan Lushan earthquake," Chinese Science Bulletin, vol. 58, no. 2829, pp. 3451-3459, 2013.

[21] F. Omori, "On the aftershocks of earthquakes," Journal of the College of Science, Imperial University of Tokyo, vol. 7, pp. 111-200, 1894.

[22] A. Kato, J. i. Fukuda, S. Nakagawa, and K. Obara, "Foreshock migration preceding the $2016 \mathrm{Mw} 7.0$ Kumamoto earthquake, Japan," Geophysical Research Letters, vol. 43, no. 17, pp. 8945-8953, 2016.

[23] H. K. Hung, R. J. Rau, E. Benedetti et al., "GPS Seismology for a moderate magnitude earthquake: lessons learned from the analysis of the 31 October 2013 ML 6.4 Ruisui (Taiwan) earthquake," Annals of Geophysics, vol. 60, Article ID S0553, 2017.

[24] R. Lloyd, J. Biggs, and A. Copley, “The decade-long MachazeZinave aftershock sequence in the slowly straining Mozambique Rift," Geophysical Journal International, vol. 217, no. 1, pp. 504-531, 2019.

[25] N. Uchida, S. H. Kirby, N. Umino, R. Hino, and T. Kazakami, "The great 1933 Sanriku-oki earthquake: reappraisal of the main shock and its aftershocks and implications for its tsunami using regional tsunami and seismic data," Geophysical Journal International, vol. 206, no. 3, pp. 1619-1633, 2016.

[26] E. Valerio, P. Tizzani, E. Carminati, and C. Doglioni, "Longer aftershocks duration in extensional tectonic settings," Scientific Reports, vol. 7, pp. 16403-403, 2017.

[27] A. Zarola and A. Sil, "Artificial neural networks (ANN) and stochastic techniques to estimate earthquake occurrences in Northeast region of India," Annals of Geophysics, vol. 60, Article ID S0658, 2017.

[28] K. Richards-Dinger, R. S. Stein, and S. Toda, "Decay of aftershock density with distance does not indicate triggering by dynamic stress," Nature, vol. 467, no. 7315, pp. 583-586, 2010.

[29] D. Kilb, V. G. Martynov, and F. L. Vernon, "Aftershock detection thresholds as a function of time: results from the ANZA seismic network following the 31 october 2001 ML 5.1 anza, California, earthquake," Bulletin of the Seismological Society of America, vol. 97, no. 3, pp. 780-792, 2007.

[30] W. J. Bosl and A. Nur, "Aftershocks and pore fluid diffusion following the 1992 Landers earthquake," Journal of Geophysical Research, vol. 107, pp. 2366-2381, 2002.

[31] C.-H. Chang, Y.-M. Wu, L. Zhao, and F. T. Wu, "Aftershocks of the 1999 chi-chi, taiwan, earthquake: the first hour," Bulletin of the Seismological Society of America, vol. 97, no. 4, pp. 1245-1258, 2007.

[32] B. Enescu, J. Mori, and M. Miyazawa, "Quantifying early aftershock activity of the 2004 mid-Niigata Prefecture earthquake (Mw6.6)," Journal of Geophysical Research, vol. 112, Article ID B04310, 2007.

[33] O. Lengliné, B. Enescu, Z. Peng, and K. Shiomi, "Decay and expansion of the early aftershock activity following the 2011, Mw 9.0 Tohoku earthquake," Geophysical Research Letters, vol. 39, Article ID L18309, 2012.

[34] T. Shirzad, "Study of fault plane using the interferometry of aftershocks: case study in the Rigan area of SE Iran," Geophysical Journal International, vol. 217, no. 1, pp. 190-205, 2019.

[35] X. B. Tan, X. W. Xu, Y. H. Lee et al., "Late Cenozoic thrusting of major faults along the central segment of Longmen Shan, eastern Tibet: evidence from low-temperature thermochronology," Tectonophysics, vol. 712-713, pp. 145-155, 2017.

[36] K. Zhang and D. Wei, "Implications from the kinematic pattern of the Longmenshan region," Tectonophysics, vol. 504, no. 1-4, pp. 57-64, 2011.

[37] M. Ishimoto and K. Iida, "Observations sur les seismes enregistres parle microsismographe construit dernierement," Bulletin of the Earthquake Research Institute, vol. 17, pp. 443-478, 1939.

[38] B. Gutenberg and C. F. Richter, "Earthquake magnitude, intensity, energy, and acceleration*," Bulletin of the Seismological Society of America, vol. 32, no. 3, pp. 163-191, 1942.

[39] T. C. Hanks, "Bvalues and $\omega-\gamma$ seismic source models: implications for tectonic stress variations along active crustal fault zones and the estimation of high-frequency strong ground motion," Journal of Geophysical Research, vol. 84, no. B5, pp. 2235-2242, 1979. 
[40] D. J. Andrews, "A stochastic fault model: 1. Static case," Journal of Geophysical Research: Solid Earth, vol. 85, no. B7, pp. 3867-3877, 1980.

[41] S. Wiemer and W. Wyss, "Minimum magnitude of completeness in earthquake catalogs: examples from Alaska, the Western United States, and Japan," Bulletin of the Seismological Society of America, vol. 90, no. 4, pp. 859-869, 2000.

[42] D. Kilb, J. Gomberg, and P. Bodin, "Triggering of earthquake aftershocks by dynamic stresses," Nature, vol. 408, no. 6812, pp. 570-574, 2000.

[43] S. Das and C. H. Scholz, "Theory of time-dependent rupture in the Earth," Journal of Geophysical Research: Solid Earth, vol. 86, no. B7, pp. 6039-6051, 1981.

[44] S. Zhu, "Is the 2013 lushan earthquake $(\mathrm{Mw}=6.6)$ a strong aftershock of the 2008 wenchuan, China mainshock (Mw=7.9)?" Journal of Geodynamics, vol. 99, pp. 16-26, 2016.

[45] B. C. Burchfiel, L. H. Royden, R. D. van der Hilst et al., "A geological and geophysical context for the Wenchuan earthquake of 12 May 2008, Sichuan, People's Republic of China," Geological Society of America Today, vol. 18, no. 7, pp. 4-11, 2008.

[46] T. Utsu, "A statistical study on the occurrence of aftershocks," Geophysical Magazine, vol. 30, pp. 521-605, 1961.

[47] A. Douglas, D. Bowers, P. D. Marshall, J. B. Young, D. Porter, and N. J. Wallis, "Putting nuclear-test monitoring to the test," Nature, vol. 398, no. 6727, pp. 474-475, 1999.

[48] L. Han, Z. Wu, C. Jiang, and J. Liu, "Properties of three seismic events in September 2017 in the northern Korean Peninsula from moment tensor inversion," Science Bulletin, vol. 62, no. 23, pp. 1569-1571, 2017.

[49] Z. Wu, P. J. Barosh, Z. Zhang, and H. Liao, "Effects from the wenchuan earthquake and seismic hazard in the longmenshan Mountains at the eastern margin of the Tibetan plateau," Engineering Geology, vol. 143-144, pp. 28-36, 2012.

[50] Q. Xu, S. Zhang, and W. Li, "Spatial distribution of large-scale landslides induced by the 5.12 Wenchuan Earthquake," Journal of Mountain Science, vol. 8, no. 2, pp. 246-260, 2011.

[51] K. Jia, S. Zhou, J. Zhuang, and C. Jiang, "Possibility of the independence between the 2013 lushan earthquake and the 2008 wenchuan earthquake on longmen Shan fault, sichuan, China," Seismological Research Letters, vol. 85, no. 1, pp. 60-67, 2014.

[52] Y. Wang, F. Wang, M. Wang, Z.-K. Shen, and Y. Wan, "Coulomb stress change and evolution induced by the 2008 wenchuan earthquake and its delayed triggering of the 2013 Mw 6.6 lushan earthquake," Seismological Research Letters, vol. 85, no. 1, pp. 52-59, 2014. 